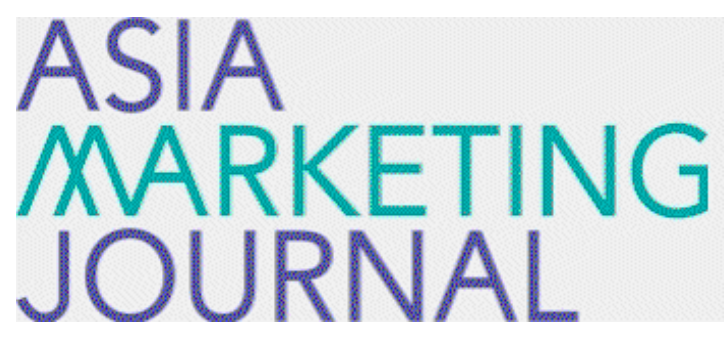

ASIA MARKETING JOURNAL

Volume 19 | Issue 1

Article 1

4-30-2017

\title{
The Impact of Consumer Evaluation on the Cause-Related Marketing
}

Chia-Lin Lee

Follow this and additional works at: https://amj.kma.re.kr/journal

Part of the Marketing Commons

\section{Recommended Citation}

Lee, Chia-Lin (2017) "The Impact of Consumer Evaluation on the Cause-Related Marketing," Asia Marketing Journal: Vol. 19 : Iss. 1 , Article 1.

Available at: https://doi.org/10.15830/amj.2017.19.1.1

This Article is brought to you for free and open access by Asia Marketing Journal. It has been accepted for inclusion in Asia Marketing Journal by an authorized editor of Asia Marketing Journal. 


\section{The Impact of Consumer Evaluation on the Cause-Related Marketing}

Chia-Lin Lee*

Cause-related Marketing (CrM) has become an increasingly popular marketing approach over the past two decades. However, neither researchers nor organizations fully understand the determinants of a successful CrM partnership. This research fills this gap. Specifically, we employ the schema theory to explore circumstances in which the CrM alliance cannot achieve a success. We use a theoretical modeling approach to report that, when consumers' typicality-based cognitive process is assumed, the CrM activity with the partners' more-discrepant attribute profile cannot be evaluated favorably, but the attribute-level uncertainty about the CrM alliance is less likely to feedback to the two partners. Furthermore, we argue that, under the schema-plus-tag model, consumers may not like the CrM program with a similar attribute profile. Therefore, this CrM approach may fail. To our knowledge, we are the first to apply the schema theory to explain how a CrM alliance can achieve a success.

Key words: Cause-related Marketing, Brand Schema, Between-partner Congruence, Attributelevel Uncertainty

\section{Introduction}

Cause-related Marketing (CrM) is an increasingly popular marketing approach, and is becoming the major tactic for firms to fulfill their social responsibility contract. Beginning in the 1980s, CrM has attracted much attention from brand managers and academic researchers as a highly valued corporate movement. For companies, a major advantage of CrM is its support of corporate philanthropy and the subsequent enhancements on corporate brand images, which can create a long-term differentiation from competitors and raise brand value (Lafferty and Goldsmith 2005). To our knowledge, there is no universally-accepted typology of the CrM activities (cf. Andreasen

\footnotetext{
* Assistant Professor, Department of Business Administration, National Chengchi University, Taiwan (clee@nccu.edu.tw)
} 
1996). In this research, we define "Causerelated Marketing" as "the partnership of a company (brand) and the cause for a specific socially-responsible marketing program, which features two names together for a customer's purchase" (cf. Gupta and Pirsch 2006).

Some well-known successful CrM programs include the CVS Corporation's cooperation with UNICEF, Yoplait's "Save Lids to Save Lives" campaign with Susan G. Komen, the Volvic's "Drink 1, Give 10" campaign with UNICEF. In most cases, successful outcomes also often enhance both partners' images. However, not all CrM programs result in a success. For instance, consumers have argued that the CrM program between Arthritis Foundation and Johnson \& Johnson's (i.e., a certain amount of sales of Arthritis Foundation Pain Relievers goes to Arthritis) affected the foundation's unbiased perspective (Andreasen 1996, p. 50). Obviously, in the failed cases, both partners in the CrM program cannot succeed in enhancing their images as well as the perceived attribute performance.

Thus, it is crucial for brand managers and academic researchers alike to understand how to achieve a success of $\mathrm{CrM}$. However, to our knowledge, the determinants for CrM success have not yet been fully identified (cf. Nowak and Clarke 2003; Robinson et al. 2012; Andrews et al. 2014). Some CrM researchers have tried to extend the findings regarding consumers' perceived fits in the brand alliance field to explore the influence of fits on CrM success (e.g., Bhattacharya and Sen 2003). Among the different types of fits defined in this research stream, the most recognized may be the "cause-brand fit", which is defined as the overall perceived congruence of the "company" (brand) and the "cause" (e.g., Rifon et al. 2004). In particular, both Lafferty (2007) and Moosmayer and Fuljahn (2013) have hypothesized that the higher the cause-brand fit (i.e., the congruence of the brand and the social cause) the more positive evaluation a CrM partnership will receive from consumers. However, both of their empirical findings do not support this hypothesis. We argue that this unresolved problem is a crucial gap in the CrM field. Because an unfavorable consumer evaluation of the CrM alliance may lead to a dilution of both partners' images, and the image dilution could be regarded as a failure of CrM (cf. Loken and John 1993).

This research bridges this gap. Specifically, we answer the unresolved problem by employing the schema theory, a well-accepted theory that helps explain consumers' cognitive process (e.g., Desai and Keller 2002). First, we identify why consumer evaluation in the scenario of a moderately-congruent $\mathrm{CrM}$ program could be better than that in the case of a similar (i.e., highly-congruent) CrM (cf. Chu et al. 2014). We show consumers' Change in Attribute-Belief (i.e., CAB) may not occur in a CrM when both partners have the same attribute profile 
and when consumers' schema-plus-tag cognitive process is assumed. We argue that, in this case, this CrM approach could fail due to an unfavorable consumer evaluation. For completing the whole picture of consumer evaluations of CrM alliances, we also investigate a morediscrepant (i.e., more incongruent) scenario. We find that, in this case, when consumers' typicality-based process is used, the CrM activity also cannot be evaluated favorably. However, consumers' attribute-level uncertainty about the CrM alliance is less likely to spill over the two partners. We use the theoretical and mathematical modeling approach to prove our theory-driven propositions so as to offer managers a normative rule and strategic intent (cf. Moorthy 1993).

The remainder of this research is organized as follows. Section 2 reviews relevant literature on corporate social responsibility, cause-related marketing, between-partner congruence, and changes in consumers' attribute-belief. Section 3 presents three research propositions. Section 4 provides the details of the mathematical analytical model we use, and show the proofs of the propositions. Section 5 presents contributions and future research directions.

\section{Literature Review}

\subsection{The Relation between Corporate Social Responsibility and Cause- related Marketing}

Definitions of corporate social responsibility (CSR) abound (Bhattacharya and Sen 2003), but CSR is often referred to as "a commitment to improve community well-being through discretionary business practices and contributions of corporate resources" (cf. Kotler and Lee 2004, p. 3). To the best of our knowledge, different classifications of CSR have been proposed by business researchers (Oeberseder et al. 2013), and, in this study, we identify four major CSR initiatives (cf. Lii and Lee 2012; Chaudary and Ali 2016), among others: community volunteering (e.g., Muthuri et al. 2009), corporate philanthropy (e.g., Szőcs et al. 2016), sponsorship (e.g., Lii and Lee 2012), and CrM activities (e.g., Kim et al. 2016). Table 1 provides a brief summary of the definitions and examples of these initiatives.

We argue that, among the various forms of CSR activities, CrM has a unique contribution to corporations due to the following two reasons. First, in contrast to sponsorship and corporate philanthropy, CrM programs are often related to consumer purchase behavior, and thus the brand can acquire the real benefits. Second, because consumers actively participate in the 
$\langle$ Table 1〉 Defitions and Examples of Four Major CSR Initiatives

\begin{tabular}{|l|l|l|l|l|}
\hline $\begin{array}{c}\text { CSR } \\
\text { Initiatives }\end{array}$ & \multicolumn{1}{c|}{$\begin{array}{c}\text { Community } \\
\text { Volunteering }\end{array}$} & \multicolumn{1}{c|}{$\begin{array}{c}\text { Corporate } \\
\text { Philanthropy }\end{array}$} & \multicolumn{1}{c|}{$\begin{array}{c}\text { Sponsorship } \\
\text { Cause-related } \\
\text { Marketing }\end{array}$} \\
\hline Definition & $\begin{array}{l}\text { "A company employee } \\
\text { devotes him- or herself to } \\
\text { the community's volunteer } \\
\text { programs" } \\
\text { (Brønn and Vrioni 2001; } \\
\text { Muthuri et al. 2009) }\end{array}$ & $\begin{array}{l}\text { "A direct contribution by } \\
\text { a corporation to a charity, } \\
\text { simply because the firm } \\
\text { wants to be a good citizen } \\
\text { without any expectation of } \\
\text { a benefit tied to that } \\
\text { effort" (Lii and Lee 2012; } \\
\text { Szőcs et al. 2016) }\end{array}$ & $\begin{array}{l}\text { "A strategic investment } \\
\text { (e.g., cash) in an activity } \\
\text { to access the exploitable } \\
\text { commercial potential } \\
\text { associated with the } \\
\text { sponsored entity or } \\
\text { event" (Lii and Lee 2012, } \\
\text { p. 71) }\end{array}$ & $\begin{array}{l}\text { "The partnership of a } \\
\text { company (brand) and the } \\
\text { cause for a specific } \\
\text { socially-responsible marketing } \\
\text { program, which features two } \\
\text { names together for a } \\
\text { customer's purchase" (Gupta } \\
\text { and Pirsch 2006) }\end{array}$ \\
\hline Examples & $\begin{array}{l}\text { Microsoft's employees } \\
\text { voluntarily teach computer } \\
\text { skills to senior high school } \\
\text { students }\end{array}$ & $\begin{array}{l}\text { Deloitte invested in pro } \\
\text { bono services for US \$110 } \\
\text { million }\end{array}$ & $\begin{array}{l}\text { The sponsorship of } \\
\text { Samsung at the 2016 Rio } \\
\text { Olympics }\end{array}$ & $\begin{array}{l}\text { Volvic's "Drink 1, Give 10" } \\
\text { campaign with UNICEF }\end{array}$ \\
\hline
\end{tabular}

"Strictly speaking, there is no commonly accepted definition for the term "corporate philanthropy" (Szôcs et al. 2016), so the activities of corporate philanthropy could overlap with other CSR initiatives.

brand's CrM activities, it is more likely that they will psychologically attach themselves to the brand (i.e., consumer - company identification; cf. Bhattacharya and Sen 2003), thus resulting in a more positive evaluation (Chaudary and Ali 2016).

\subsection{Relevant Literature in Cause-related Marketing}

$\mathrm{CrM}$ is considered one type of brand alliance (e.g., Lafferty and Goldsmith 2005), thus many scholars utilized brand alliance research theory and knowledge (e.g., Simonin and Ruth 1998; Voss and Gammoh 2004; Gammoh et al. 2006) to assess how consumers evaluate CrM activities (e.g., Lafferty et al. 2004). To our knowledge, two major research streams comprise this field.
A major research stream focuses on the importance and influences of the "cause". For example, in this stream, some scholars separated the "cause" into two groups: the primary "cause" (e.g., health, safety) and the secondary "cause" (e.g., economic development and employment), and argued that consumers may perceive these two types of causes differently. Both Demetriou et al. (2010) and Cornwell and Coote (2005) reported that use of a primary cause can achieve a more successful outcome than the use of a secondary cause. Another interesting issue relevant to the "cause" selection is about the location of the "cause". For example, using the social exchange theory, Ross et al. (1991) found that US people prefer a local cause (i.e., US-based) to a global-based cause, because people tend to choose to support causes relevant to their self-interests, which 
are usually "closer to home". Furthermore, researchers have also explored the different influences of the "continuous-tragedy" cause on consumer evaluation of CRM programs (e.g., AIDS/HIV in Africa) and the "suddendisaster" cause, such as the 2011 earthquake disaster in Japan. Both Ellen et al. (2000) and Cui et al. (2003) found that CRM marketing programs of a "disaster" cause are more likely to result in more positive consumer evaluation of the CRM partners than a "continuoustragedy" cause.

The other major research stream, from consumer psychology perspective, emphasizes the importance of consumers' perceived fit between the "company" (brand) and the "cause". To the best of our knowledge, CrM researchers have identified at least three types of fits, namely the cause-customer, brandcustomer, and cause-brand fit.

The cause-customer fit can be defined as "the relevance between consumers' personal meaning/value and the image of the cause" (cf. Gupta and Pirsch 2006). Some studies (e.g., Goldsmith and Zhu 2014) have posited that when a larger level of cause-customer fit exists, consumer evaluation of the CrM program is more positive than in a lower-fit scenario. In addition to the cause-customer fit, customerbrand fit refers to the overall relatedness or congruence between consumers' self-concept and the company's image (e.g., Bhattacharya and Sen 2003). Gupta and Pirsch (2006) argue that the customer-brand fit positively moderates consumers' purchasing intent at different congruence levels between the cause and the company (brand) in a CrM program.

Maybe the most influential fit is the causebrand fit (e.g., Hamlin and Wilson 2004; Rifon et al. 2004; Lafferty 2007). This term can be defined as "the perceived congruence between cause and the company". Hamlin and Wilson (2004) reported that the congruence level between the cause and the brand strongly affects consumer evaluation. Except for the congruence level in product categories, the congruence level for both partners' images also matters. For example, Rifon et al. (2004) argued that the congruence level of the social cause and the brand (sponsor) on brand-level associations could affect consumer evaluation of the brand (sponsor). Lafferty et al. (2004) reported that the CrM's performance could increase if the marketed images of both partners are similar. Both Lafferty (2007) and Moosmayer and Fuljahn (2013) argued that a high congruence level between the brand's and the cause's image leads to a high and positive evaluation of the company/brand. However, their empirical studies did not support this argument. We argue that this is a crucial gap, because cause-brand fit is a very important factor to the CrM success (cf. Crimmins and Horn 1996). 


\subsection{Between-Partner Congruence and Changes in Attribute-Belief}

Indeed, the brand alliance literature have already examined between-partner congruence. Walchli (2007) has reported that the most favorable consumer evaluations go to the moderately-congruent brand pair, and that highly-incongruent and highly-similar partnerships score lower on attitudinal favorability. Geylani et al. (2008) confirmed Walchli's (2007) findings. The authors examined this issue on the attribute-belief level, and showed that the allying brands would have a positive "Change in Attribute-Belief" (in the following, CAB) in this moderately-congruent pair. They concluded that the best decision for one brand is to choose a partner with only a moderatelydifferent attribute profile due to the possibility of enhancing its perceived attribute performance and the associated brand image, brought by the $\mathrm{CAB}$. We argue that, in a co-operative marketing partnership (e.g., brand alliance or CrM), CAB may be crucial to alliance success. That is, a positive $C A B$ could enhance both partners' images, and a lack of $\mathrm{CAB}$ could lead to a failure.

Note that, hereafter in this research, the term "congruence" will be referred to as the similarity or consistency between the two partners' performance of functional attributes (e.g., the possible negative image of Bayer brought by its products) or the symbolic perceptions (e.g., beneficial to the environment of Whole-foods delivered by the advertisements). That is, we do not consider other aspects of between-partner congruence (e.g., the industryimage; cf. Burmann et al. 2008).

\section{Propositions}

In this section, we employ schema theory to develop theory-driven propositions for explaining why a larger level of between-partner congruence cannot lead to a more positive consumer evaluation, and may result in the CrM failure. Marketing scholars have utilized the schema theory to explore consumers' cognitive perception change in brand extension (e.g., Gürhan-Canli and Maheswaran 1998). We argue that consumers' perceived performance level of important attributes (i.e., attribute beliefs; Geylani et al. 2008) is a key component of brand schema (cf. De Ruyter and Wetzels 2000). To our knowledge, little research has explored the brand schema concept in the CrM research field.

There are mainly two major models of brand schema change. The first is the schema-plustag (e.g., Desai and Keller 2002). The schemaplus-tag model explains how consumers update (i.e., revise) their existing attribute beliefs about a brand when they receive new information of that brand (e.g., a new release of the 
extended product; e.g., Apple's sofa). In particular, this model shows that the more (less) inconsistent the new information is with consumers' current attribute beliefs of the brand, the larger (smaller) their CAB. In the CrM context, we predict that the same result may occur, as expressed in Proposition 1 (Prop. 1).

\subsection{Proposition 1}

When a schema-plus-tag cognitive process is assumed, and when the partners in a causerelated marketing alliance are more similar in terms of attribute profile, consumers are less likely to change their attribute beliefs. Consequently, this CrM approach may fail due to the lack of $C A B$.

Prop. 1 posits that, in a highly-similar scenario, consumers may feel this partnership redundant and may negatively evaluate this partnership (cf. Walchli 2007). Thus, CAB will not occur because consumers have no interests in this pair. Thus, we argue that this highly-congruent partnership can lead to a failure, because the partners have no opportunity to enhance their attribute profiles (i.e., no-CAB occurs) in this partnership. That is, the brand partners have no incentives for alliance formation. Note that Prop. 1 bridges the gap in Lafferty (2007) and Moosmayer and Fuljahn (2013), because it helps explain why a larger level of the cause- brand fit - in terms of between-partner congruence - cannot be evaluated more positively by consumers in the CrM context.

To get the picture, we utilize the other model of brand schema change, the typicalitybased model, to explain why consumer will not have a positive evaluation of the highlyincongruent CrM.

In comparison with the schema-plus-tag model, the typicality-based model (Rothbart and Lewis 1988; Loken and John 1993) shows that consumers tend to regard the new information of one brand as atypical to that brand, when the new information is regarded highly-inconsistent with their current knowledge of that brand (e.g., Loken and John 1993). For instance, if consumers associate "Neutrogena" as a "mild" brand, they are possible to regard a strong and harsh Neutrogena shampoo as an atypical product of Neutrogena. We argue that the same result may occur in the CrM context. Proposition 2 (Prop. 2) describes this argument.

\subsection{Proposition 2}

When consumers' typicality-based cognitive process is assumed, and when the partners in a cause-related marketing alliance have a more incongruent attribute profile, this CrM alliance may be evaluated less favorably by consumers.

Prop. 2 posits that, when the CrM partners 
appear to be different (e.g., a tobacco company aligns with a smoke-free campaign held by a non-profit organization), consumers may have difficulty in understanding why this discrepant partnership is established and will negatively evaluate the partnership (cf. Walchli 2007).

Under this scenario, we would like to also address the impacts of attribute uncertainty on consumer evaluation (e.g., Park et al. 1996; Geylani et al. 2008). Marketing scholars have commonly accepted that attribute uncertainty (i.e., the perceived variability in an attribute) affects consumer evaluations of one brand/ product (e.g., Meyer 1981). In particular, when an existing brand releases a new extended product, consumers may have difficulties in predicting the real performance level of an important attribute that the brand already excels (e.g., consumers may be uncertain about the true performance of the attribute "mildness" when Neutrogena extends from the soap category to the conditioner category; cf. Geylani et al. 2008). The underlying reasons behind the attribute unreliability could be idiosyncratic perceptions (cf. Erdem and Keane 1996) or the inherent product variability (cf. Roberts and Urban 1988; Erdem and Keane 1996). In the co-branding context, Park et al. (1996) have argued that consumers may be confused with the real attribute performance of the co-branded products, when the partnering brands have incongruent attribute performance or profiles. Geylani et al. (2008) further posited that the degree of the unreliability about the co-branded products is positively influenced by the level of the attribute-level difference between the two brand partners (i.e., the incongruence between two brands). The authors also reported that the uncertainty about the attribute beliefs about the co-brand can reflect back on the perceived attribute levels of each partner. However, they inferred that (p. 735), when the typicality-based model is used and the attribute profiles of the two brands are highly-incongruent, consumers tend to not bring the uncertainty about the attribute beliefs about the co-brand to each of the two partnering brands after the co-branded product releases. We argue that the same pattern may occur also in the CrM context, and Proposition 3 (Prop. 3) describes this argument.

\subsection{Proposition 3}

When consumers' typicality-based cognitive process is assumed, and when the partners in a cause-related marketing alliance have a more incongruent attribute profile, consumers' uncertainty about the CrM is less likey to reflect back to the two partners.

Prop. 3 infers that, under the typicalitybased model, when consumers consider one brand's new information highly-inconsistent with their current brand knowledge (i.e., the extreme case), they will deem the new branded 
information atypical. As mentioned in Prop. 2, in this case, consumers may have no inclination to resolve the high discrepancy (cf. Walchli 2007), and thus $C A B$ does not occur. We argue that when the typicality-based model is used and the attribute profiles of partners are highly-incongruent, consumers may also skip and neglect the uncertainty of the CrM alliance. Consequently, both partners may not suffer from the alliance. Note that it is difficult to find a real case corresponding to this proposition, and the hypothetical example of this scenario can be the CrM alliance formed by Bayer and Whole-Foods (i.e., a highly incongruence of "doing good for the earth") or the CrM partnership established by Bayer and the Susan G. Komen Foundation (i.e., a highly inconsistency of "good for the health"). In both cases, we argue that consumers may have a rather small interest in the partnerships, and thus the uncertainty of the CrM alliance does not reflect back to each partner.

\section{Research Method}

\subsection{Model Setting}

In this section, we will use the theoretical modeling approach to prove the three propositions. We begin our model by assuming that $B$ (brand) and $C$ (cause) are the prospective partners $(Z \in\{B, C\})$ of building an "causerelated" marketing alliance; this partnership is assumed to be established at time point $i=1$, and, at $i=2$, this marketing program has already been performed. Besides, consumers use two attributes, denoted by $G(G \in\{x, y\})$, to evaluate the two partners: $x$ represents the attribute of "doing good for the earth", and $y$ is referred to as the attribute of "brand awareness" (cf. Kim et al. 2015). Note that we consider "brand awareness" is an important attribute, because Macdonald and Sharp (2000) reported that this attribute plays an important role in explaining consumer choice behavior.

We use the expectancy-value model (e.g., Bass and Talarzyk 1972) to formulate consumer evaluation of the two partners. That is, consumers' preference score, $\theta_{Z(i)}$ is modeled as a parameter consisting of consumers' attribute importance weight, $\varepsilon_{Z}^{G}>0$, and consumers' beliefs of each attribute of each partner, $\left.W_{Z(i)}^{G}\right\rangle$ 0 . By assuming a homogeneous nature of consumer preference, each partner's preference score can be represented as follows:

$$
\theta_{Z(i)}=\sum_{G} \varepsilon^{G} \times W_{Z(i)}^{G}
$$

In the following we will use Eq. (1) to formulate three types of consumer evaluations, - before-alliance evaluation, the evaluation of the CrM, and after-alliance evaluation. First, the before-alliance evaluation is modeled as 


$$
W_{B(1)}^{x}<W_{C(1)}^{x}
$$

Note that Eq. (2) is an important motive for the partners in this alliance, because normally the company will choose to ally with the cause with the higher perceived performance level of "doing good for the earth" for improving the image. However, Eq. (2) also represents a certain level of incongruence (or congruency) between the two partners. We use $\lambda^{G}$ to denote the consumer's attribute-level difference of attribute $G$ between $B$ and $C$ at $i=1$. That is, we define

$$
\lambda^{G}=\left|W_{B(1)}^{G}-W_{C(1)}^{G}\right|
$$

Thus, $\lambda^{G}$ is formulated as a continuous function of $W_{Z(i)}^{G}$, and, in the following, we will use $\lambda^{G}$ to model the magnitude of (in) congruence between the two partners in this CrM alliance. That is, according to Lafferty (2007), when $\lambda^{G}$ decreases, a higher level of cause-brand fit exists (i.e., a larger level of between-partner congruence on both partners' image occurs). In contrast, when $\lambda^{G}$ increases, a lower level of cause-brand fit exists.

Now we deal with the consumer evaluation of the "cause-brand" marketing alliance. By applying the information integration theory (Anderson 1981), we can model consumers' beliefs about the alliance by integrating their existing beliefs (cf. Geylani et al. 2008). So,

$$
W_{B C}^{G}=\left(1-\kappa_{Z}^{G}\right) W_{B(1)}^{G}+\kappa_{Z}^{G} W_{C(1)}^{G}+\sigma .
$$

That is, in Eq. (4), $\kappa_{Z}^{G}$ denotes the contributing weight of each attribute of each partner to the CrM beliefs. Besides, a random term, $\sigma$, is added in Eq. (4) to denote consumers' confusion about the true attribute levels (i.e., attribute uncertainty; cf. Park et al. 1996; Geylani et al. 2008). We further assume that this confusion term is uniformly distributed on the interval $[-\tau, \tau]$ (cf. Geylani et al. 2008).

Consumers' after-alliance evaluation can be formulated as a parameter consisting of consumers' before-alliance beliefs and CrM evaluation (cf. anchoring-and-adjustment; Song 2017). So, Eqs. (5) and (6) show customers' after-alliance evaluation of each partner:

$$
\begin{aligned}
& W_{Z(2)}^{x}=\delta_{Z}^{x} \times W_{B C}^{x}+\left(1-\delta_{Z}^{x}\right) \times W_{Z(1)}^{x}, \\
& W_{Z(2)}^{y}=\delta_{Z}^{y} \times W_{B C}^{y}+\left(1-\delta_{Z}^{y}\right) \times W_{Z(1)}^{y} .
\end{aligned}
$$

In Eqs. (5) and (6), we use $\delta_{Z}^{G}\left(1 \geq \delta_{Z}^{G} \geq 0\right)$ to denote the updating weight, and the different value of $\delta_{Z}^{G}$ shows the quantity of the consumers' $\mathrm{CAB}$.

\subsection{Proofs}

In this sub-section, we will prove the three propositions. Note that hereafter we analyze only the $\mathrm{CAB}$ of one brand; thus, we drop 
index $Z$. By using the above specifications, we prove Prop. 1 as follows.

First, the schema-plus-tag model can be mathematically formulated by Eq. (7):

$$
\left(\partial \delta^{G} / \partial \lambda\right)>0
$$

Eq. (7) shows that that $\mathrm{CAB}\left(\delta^{G}\right)$ changes positively with the difference of attribute-level of two brands. Assuming that $\lambda \mapsto \delta^{G}(\lambda)$ is a monotonic decreasing function and that $\delta^{G} \in$ $(0,1)$. So, if $\lambda=0, \delta^{G}$ reaches the lower bound, 0 . In this scenario, CAB does not exist, and thus both brand partners would not have incentives to form an alliance (cf. Venkatesh et al. 2000).

Prop. 2 can be proved as follows. In contrast to Eq. (7), we formulate the typicality-based model by Eq. (8):

$$
\left(\partial \delta^{G} / \partial \lambda\right)<0
$$

That is, Eq. (8) shows that consumers can less negatively evaluate the partnership (cf. Walchli 2007) if the CrM partners appear to be more different. To prove Prop. 3, first we also assume that Eq. (8) is valid. Besides, we assume that $\tau$ is strictly decreasing in $\delta^{G}$. That is,

$$
\left(\partial \tau / \partial \delta^{G}\right)<0
$$

According to Eqs. (8) and (9), one can easily observe that $(\partial \tau / \partial \lambda)>0$. If we further assume that the lower bound of $\tau$ is 0 . Then, we can show that $\tau$ achieves 0 when $\lambda$ goes to infinity. In this case, consumers' confusion about the attribute beliefs $(\sigma)$ about the co-brand will not reflect back to each of the two partners.

\section{Contributions and Future Research Directions}

This research bridges a crucial gap in the Cause-related Marketing (CrM) research field. Specifically, we explore why a better causebrand fit in terms of a higher level of betweenpartner congruence (i.e., similar) cannot result in a more positive consumer evaluation. We employ the schema theory to offer three propositions. The first proposition states that, when consumers' schema-plus-tag cognitive process is assumed, a similar CrM program may not be evaluated favorably by consumers. We argue that in this case, consumers' Change in Attribute-Beliefs (CAB) may not happen for the two brands; thus, this scenario could be a failure. The second and third propositions posit that, under the typicality-based cognitive process, the CrM partnership with a morediscrepant attribute profile may lead to an unfavorable consumer evaluation. However, consumers' confusion or attribute uncertainty 
about the CrM alliance is less likely to spill over each of the partner; In sum, it is difficult to conclude whether this scenario succeeds or not, from the perspective of consumer psychology. To the best of our knowledge, this study makes two distinct contributions to the CrM research field. First, we are the first to apply the schema theory to explain the underlying reasons behind a CrM success. Secondly, we address the importance of "image-transfer" in the CrM field, and thus echo Andreasen (1996, p. 51) by arguing that the cause may be affected by its partners in the moderatelycongruent scenario.

For the marketing managers, this study provides a normative guideline of a CrM approach. We suggest that the marketing managers of the "cause" always take the influence of between-partner congruence into considerations. From Prop. 1 and Prop. 2, we can conclude that the optimal CrM pair is the one with a moderately-difference in terms of the perceived attribute profiles. That is, based on our findings, the brand has to know how to select a causebased organization that is not too similar and not extremely-different. So, the brand may consider cooperating with an international cause if there are no suitable local or national causes. However, in this case, the brand should mind the negative impact of cause scope (cf. Cui et al. 2003). That is, consumers may have a more favorable evaluation of a local cause than an international one. Besides, according to Prop. 3, under the typicality-based cognitive process, consumers' attribute-level uncertainty about a highly-inconsistent CrM pair may not feedback to the two partners. In this case, the occurrence of a no-feedback effect may be good for the cause, because, most of the time, it is the cause who lends the "positve" brand image for the company to improve its image of philanthropy. Therefore, the cause may be afraid of the occurrence of a magnified "uncertainty" of its positive brand image. In summary, according to Prop. 2 and Prop. 3, under the typicalitybased cognitive process, consumers may not like CrM activity with the partners' highlydifferent attribute profile; however, consumers' attribute-level uncertainty about the CrM alliance may not feedback to the two partners. This paper is not without limitations. First, because this research aims to provide the strategic intent of CrM strategy (cf. Moorthy 1993), we have not provided an empirical validation of our propositions. Here, we offer further steps of a possible empirical investigation. First of all, consumers' previous attribute beliefs about the hypothetical brand and the cause $\left(W_{Z(i)}^{G}\right)$ could be primed by constructing a frequency chart of ratings (cf. Yi 1990; Geylani et al. 2008, p. 736), and consumers' attribute importance weight $\left(\varepsilon_{Z}^{G}\right)$ could be collected by using the constant sum scaling (cf. Mackenzie 1986). In doing so, we can measure consumers' before-alliance preference score $\left(\theta_{Z(1)}\right)$. Then, we can use an advertisement 
(cf. Simonin and Ruth 1998) to present the CrM partnership to the responsdents, and gather consumers' attribute beliefs about $\left(W_{B C}^{G}\right)$ and the possible confusions with this CrM partnership $(\sigma)$. Finally, the respondents will be asked to again report their after-alliance attribute beliefs and the uncertainty of each partner (cf. Geylani et al. 2008; Lee 2014). So, researchers may follow the above-mentioned procedures to test our propositions.

Secondly, due to the need of parsimony of our mathematical model (Venkatesh et al. 2000), we do not examine the level of incongruence or similarity from every aspect of the diversed dimensions. For example, future studies could address the "industry-image" of the partners (e.g., Dowling 1993), and examine whether our theory-driven propositions are still effective under the scenarios in which both partners' industry-images are similar (cf. Burmann et al. 2008, p. 172). Last but not least, we have not included the important variable of brand familiarity (e.g., Lafferty et al. 2004), because currently we instead focus on the impacts of between-partner congruence.

〈Received December 17. 2016〉

〈Revised March 27. 2017〉

〈Accepted March 30. 2017〉

\section{References}

Anderson, N. H. (1981). Foundation of Information Integration Theory. New York: Academic Press.

Andreasen, A. R. (1996). Profits for nonprofits: find a corporate partner. Harvard Business Review, 74(6), 47-50.

Andrews, M., Luo, X., Fang, Z., \& Aspara, J. (2014). Cause marketing effectiveness and the moderating role of price discounts. Journal of Marketing, 78(6), 120-142.

Bass, F. M., \& Talarzyk, W. W. (1972). An attitude model for the study of brand preferences. Journal of Marketing Research, 9(1), 93-96.

Bhattacharya, C. B., \& Sen, S. (2003). Consumercompany identification: a framework for understanding consumers' relationships with companies. Journal of Marketing, 67(2), 76-88.

Brønn, P. S., \& Vrioni, A. B. (2001). Corporate social responsibility and cause-related marketing: an overview. International Journal of Advertising, 20(2), 207-222.

Burmann, C., Schaefer, K., \& Maloney, P. (2008). Industry image: its impact on the brand image of potential employees. Journal of Brand Management, 15(3), 157-176.

Chaudary, S., \& Ali, M. (2016). The spillover effect of CSR initiatives on consumer attitude and purchase intent: the role of 
customer-company identification with the moderating effect of awareness. Pakistan Journal of Commerce and Social Sciences, 10(2), 368-387.

Chu. K. H., Lee, D. H., Yeu, M. S., \& Park, S. T. (2014). How much change is optimal when a brand is newly rebranded?. Asia Marketing Journal, 15(4), 161-186.

Cornwell, T. B., \& Coote, L. V. (2005). Corporate sponsorship of a cause: the role of identification in purchase intent. Journal of Business Research, 58(3), 268-276.

Crimmins, J., \& Horn, M. (1996). Sponsorship: from management ego trip to marketing success. Journal of Advertising Research, 36(4), 11-22.

Cui, Y., Trent, E. S., Sullivan, P. M., \& Matiru, G. N. (2003). Cause related marketing: how generation $\mathrm{Y}$ responds. International Journal of Retail \& Distribution Management, 31(6), 310-320.

De Ruyter, K., \& Wetzels, M. (2000). The role of corporate image and extension similarity in service brand extensions. Journal of Economic Psychology, 21(6), 639-659.

Demetriou, M., Papasolomou, I., \& Vrontis, D. (2010). Cause-related marketing: building the corporate image while supporting worthwhile causes. Journal of Brand Management, 17(4), 266-278.

Desai, K. K., \& Keller, K. L. (2002). The effects of ingredient branding strategies on host brand extendibility. Journal of Marketing,
66(1), 73-93.

Dowling, G. R. (1993). Developing your company image into a corporate asset. Long Range Planning, 26(2), 101-109.

Ellen, P. S., Mohr, L. A., \& Webb, D. J. (2000). Charitable programs and the retailer: do they mix?. Journal of Retailing, 76(3), 393-406.

Erdem, T., \& Keane, M. P. (1996). Decisionmaking under uncertainty: capturing dynamic brand choice processes in turbulent consumer goods markets. Marketing Science, 15(1), 1-20.

Gammoh, B. S., Voss, K. E., \& Chakraborty, G. (2006). Consumer evaluation of brand alliance signals. Psychology \& Marketing, 23(6), 465-486.

Geylani, T., Inman, J. J., \& Hofstede, F. T. (2008). Image reinforcement or impairment: the effects of co-branding on attribute uncertainty. Marketing Science, 27(4), 730-744.

Goldsmith, R. E., \& Zhu, Y. (2014). The influences of brand-consumer and causecongruence on consumer responses to cause related marketing. Journal of Applied Marketing Theory, 5(2), 74-95.

Gupta, S., \& Pirsch, J. (2006). A taxonomy of cause-related marketing research: current findings and future research directions. Journal of Nonprofit \& Public Sector Marketing, 15(1/2), 25-43.

Gürhan-Canli, Z., \& Maheswaran, D. (1998). 
The effects of extensions on brand name dilution and enhancement. Journal of Marketing Research, 35(4), 464-473.

Hamlin, R. P., \& Wilson, T. (2004). The impact of cause branding on consumer reactions to products: does product/cause "fit" really matter?. Journal of Marketing Management, 20(7/8), 663-681.

Kim, S. B., Kim, K. J., \& Kim, D. Y. (2016). Exploring the effective restaurant CrM ad: the moderating roles of advertising types and social causes. International Journal of Contemporary Hospitality Management, 28(11), 2473-2492.

Kim, C., Seo, E., Hong, J., Kang, S., \& Newell, S. J. (2015). The antecedents and consequences of effective brand positioning. Asia Marketing Journal, 17(3), 33-51.

Kotler, P., \& Lee, N. (2004). Corporate Social Responsibility: Doing the Most Good for Your Company and Your Cause. New Jersey: John Wiley and Sons.

Lafferty, B. A. (2007). The relevance of fit in a cause-brand alliance when consumers evaluate corporate credibility. Journal of Business Research, 60(5), 447-453.

Lafferty, B. A., \& Goldsmith, R. E. (2005). Cause-brand alliances: does the cause help the brand or does the brand help the cause?. Journal of Business Research, 58 (4), 423-429.

Lafferty, B. A., Goldsmith, R. E., \& Hult, G. T. M. (2004). The impact of the alliance on the partners: a look at cause-brand alliances. Psychology \& Marketing, 21(7), 509-531.

Lee, C.-L. (2014). Is co-branding a doubleedged sword for brand partners?. European Research Studies Journal, 17(4), 19-34.

Lii, Y. S., \& Lee, M. (2012). Doing right leads to doing well: when the type of CSR and reputation interact to affect consumer evaluations of the firm. Journal of Business Ethics, 105(1), 69-81.

Loken, B., \& John, D. R. (1993). Diluting brand beliefs: when do brand extensions have a negative impact?. Journal of Marketing, 57(3), 71-84.

Macdonald, E. K., \& Sharp, B. M. (2000). Brand awareness effects on consumer decision making for a common, repeat purchase product: a replication. Journal of Business Research, 48(1), 5-15.

Mackenzie, S. B. (1986). The role of attention in mediating the effect of advertising on attribute importance. Journal of Consumer Research, 13(2), 174-195.

Meyer, R. J. (1981). A model of multiattribute judgments under attribute uncertainty and informational constraint. Journal of Marketing Research, 18(4), 428-441.

Moorthy, K. S. (1993). Theoretical modeling in marketing. Journal of Marketing, 57(2), 92-106.

Moosmayer, D. C., \& Fuljahn, A. (2013). Corporate motive and fit in cause related 
marketing. Journal of Product \& Brand Management, 22(3), 200-207.

Muthuri, J. N., Matten, D., \& Moon, J. (2009). Employee volunteering and social capital: contributions to corporate social responsibility. British Journal of Management, 20(1), 75-89.

Nowak, L. I., \& Clarke, T. K. (2003). Causerelated marketing: keys to successful relationships with corporate sponsors and their customers. Journal of Nonprofit \& Public Sector Marketing, 11(1), 137-149. Oeberseder, M., Schlegelmilch, B. B., \& Murphy, P. E. (2013). CSR practices and consumer perceptions. Journal of Business Research, 66(10), 1839-1851.

Park, C. W., Jun, S. Y., \& Shocker, A. D. (1996). Composite branding alliances: an investigation of extension and feedback effects. Journal of Marketing Research, 33 (4), 453-466.

Rifon, N. J., Choi, S. M., Trimble, C. S., \& Li, H. (2004). Congruence effects in sponsorship: the mediating role of sponsor credibility and consumer attributions of sponsor motive. Journal of Advertising, 33(1), 30-42.

Roberts, J. H., \& Urban, G. L. (1988). Modeling multiattribute utility, risk, and belief dynamics for new consumer durable brand choice. Management Science, 34(2), 167185.

Robinson, S. R., Irmak, C., \& Jayachandran, S. (2012). Choice of cause in cause-related marketing. Journal of Marketing, 76(4), 126-139.

Ross, J. K., III, Stutts, M. A., \& Patterson, L. T. (1991). Tactical considerations for the effective use of cause-related marketing. Journal of Applied Business Research, 7 (2), 58-65.

Rothbart, M., \& Lewis, S. (1988). Inferring category attributes from exemplar attributes: geometric shapes and social categories. Journal of Personality and Social Psychology, 55(6), 861-872.

Simonin, B. L., \& Ruth, J. A. (1998). Is a company known by the company it keeps? Assessing the spillover effects of brand alliances on consumer brand attitudes. Journal of Marketing Research, 35(1), $30-42$.

Song, J. D. (2017). An exploratory study on the effect of price as an anchor on willingness-to-pay. Asia Marketing Journal, 18(4), 27-49.

Sző́cs, I., Schlegelmilch, B. B., Rusch, T., \& Shamma, H. M. (2016). Linking cause assessment, corporate philanthropy, and corporate reputation. Journal of the Academy of Marketing Science, 44(3), 376-396.

Venkatesh, R., Mahajan, V., \& Muller, E. (2000). Dynamic co-marketing alliances: when and why do they succeed or fail. International Journal of Research in Marketing, 17(1), 3-31.

Voss, K. E., \& Gammoh, B. S. (2004). Building 
brands through brand alliances: does a second ally help?. Marketing Letters, 15 (23), 147-159.

Walchli, S. B. (2007). The effects of betweenpartner congruity on consumer evaluation of co-branded products. Psychology \& Marketing, 24(11), 947-974.

Yi, Y. (1990). Cognitive and affective priming effects of the context for print advertisements. Journal of Advertising, 19(2), 40-48. 